\title{
Load Balancing on TJSB Transformer Distribution Using Two-Points Time Method
}

\author{
Jimmy Trio Putra, Mohammad Arsyad Sidiq \\ Department of Electrical Engineering and Informatics, Universitas Gadjah Mada \\ Sekip Unit IV, Yogyakarta, Indonesia 55281 \\ e-mail: jimmytrioputra@ugm.ac.id, mohammadarsyad10@gmail.com
}

\begin{abstract}
The load unbalances is caused by single phase loads on low voltage network consumers. In the design of three-phase transformer loads are generally designed in a balanced way, but in reality that occurs, the distribution of transformer load in the network is not balanced. This unbalance can lead the current to flow in a neutral conductor if not observed accordingly. The flowing current in the transformer's neutral conductor can cause losses. This paper discusses load balancing using the two-point time method as a recommendation for moving the consumer's load from one phase to another phase. This study used real data by performing direct measurements on the loading of TJSB transformer Pabuaran feeder of PT (PLN) Persero Sukabumi Region both before and after the load balancing. The results obtained after the load balancing include the percentage of unbalance during the day that is $5 \%$ which was previously $16 \%$ and at night become $5.6 \%$ from $25.6 \%$. The initial neutral current was $44 \mathrm{~A}$ and decreased to be $16 \mathrm{~A}$ during the day, while at night decreased from $68 \mathrm{~A}$ to $24 \mathrm{~A}$. Power losses due to neutral currents flowing in the neutral conductor obtained at noon i.e. $0.19 \mathrm{~kW}$ from previously $1.32 \mathrm{~kW}$ and at night $0.39 \mathrm{~kW}$ from the previous $2.3 \mathrm{~kW}$.
\end{abstract}

Keywords: neutral current; load unbalances; load losses.

\section{Introduction}

Local transformers supply electrical transmission system to the consumer. The consumers, either residential or commercial establishments, are the end users, get the electricity from secondary distribution circuits. Phase scheduling to balance the system is needed because of differences in loads consumption of commercial and residential, which are mainly single phase, with the three phases main feeders [1].

The load may change because of new applications of heavy-duty appliances like air conditioners as the part of living style changes mostly in one certain phase only. This is lead to a high amount of neutral current in cables because the total currents are not equal to zero.

Unbalanced loading caused some current passing through the neutral wire that is burnt if it exceeds the capacity. The power outage occurs until the wire is replaced. There are two ways to prevents and solve this problem, one of that is increasing the size of the neutral wire thus the possibility of overloaded neutral wires can be depleted. Second and also the best way, balancing the loads on the 3 phases to eliminate the neutral until nearly zero [2].

The studies about load balancing in distribution systems are discussed in [3]. The method changes the open/closed status of sectionalizing and ties switches with big data used to solve problem load unbalance in distribution systems. The calculation overload index of all the possible operation modes thus it is obtained the most appropriate strategy. Researcher [4] used 3-D and 2D FEM in evaluating and de-rating of three-phase distribution transformer under unbalanced voltage and unbalance load. In paper [5], proposes a methodology by automatic phase load balancing in eight realistic three phases transformer with a different power rating. Distribution systems connected with a distributed generator which is need voltage balance during single-phase auto-reclosing (SPAR) by zigzag transformer's method is discussed in [6]. The load balancing of distribution transformers can increase the operation efficiency of distribution systems is introducing by the paper [7]. Researcher [8] found that High PV Penetration can significantly extend the Distribution Transformer Insulation Life. In paper [9], discussed optimal switching operation can be obtained very efficiently for load balancing in the distribution network by a coloured Petri net algorithm (CPN). Time domain and time-sequence power flow simulations applied for load balancing of radial distribution systems by controlling non-synchronous micro-grids are discussed 
by paper [10]. Researcher [11], proposes to balance the power of multiple transformers in lowvoltage distribution systems by multi-bus flexible interconnection scheme.

This research was conducted by measuring the current, voltage and resistance of Tanjung

Sari Baru (TJSB) transformer, analyses the load unbalance, neutral current and power loss. Furthermore, an analysis was conducted using a two-point time method as a recommendation for balancing the transformer load. Based on the recommendation, loads movement into a particular phase transformer was completed. Furthermore, we performed a load balancing analysis of load movement from one phase to another phase. This study used real data in the field by measuring directly to the loading of the transformer TJSB Pabuaran feeder of PT (PLN) Persero Sukabumi Region both before and after the load balancing.

\section{Two-points Time Method}

\subsection{Load Unbalance}

Load unbalances occurs when one or two conditions of balance situation fail to be fulfilled. The possibilities are three:

a. The three vectors are equally large but do not form an angle of $120^{\circ}$ to each other,

b. The three vectors are not equally large but form an angle of $120^{\circ}$ to each other,

c. The three vectors are not equally large and do not form an angle of $120^{\circ}$ to each other.

\subsection{Power Losses Caused by Neutral Current}

The flowing current in the transformer's neutral conductor is caused by load unbalance in the phases of the secondary side of the transformer (R, S, and T) and this causes electrical power losses. Loss of this transformer neutral transmitter can be formulated:

$$
P_{N}=I_{N}^{2} \cdot R_{N}
$$

While the power losses caused by neutral current flew to the ground can be formulated:

$$
P_{G}=I_{G}^{2} \cdot R_{G}
$$

\subsection{Two-points Time Method}

Two-points time method is a determination method that can be a recommendation in load balancing of a distribution transformer. This method uses the concept of measurement of load data served by the transformer by using two times i.e. day and night. The objective is to compare with the load used during base load and peak load. The two-point time method is devoted only to balancing substations that serve residential type loads.

Planning and determining the amount of burden that must be shared and transferred to the distribution station become recommendations of this method. The flow chart of the two-point time method is shown in Fig. 1.

\section{Test System}

The researcher took real data in Sukabumi Kota Region of PT PLN (Persero). Load measurement was done using ampere pliers in Pabuaran feeder, specifically in TJSB (Tanjung Sari Baru) Substation. Single Line diagram of Pabuaran feeder refers to Fig. 2. Substation load was determined in two-time points: day (10.00-15.00 WIB) and night (19.00-20.30 WIB). For each time point, 3 times of determination with 5 minutes' gap between initial determination and the followings were done. Obtained TJSB transformer's current, voltage and resistance data are explained below:

\subsection{Transformer}

Transformation specifications of TJSB substation are shown in Table 1. Transformer obtains supply from Pabuaran feeder-Lembur Situ Substation by radial network system as shown in Fig. 2. The Radial system has an advantage in a situation when maintenance has happened or there is interference at the network at one point, a total blackout is unnecessary but manoeuvres in $\mathrm{GH}$. CIPOHO and GH. BPS is possible to be conducted. 
Jurnal IImu Teknik Elektro Komputer dan Informatika (JITEKI)

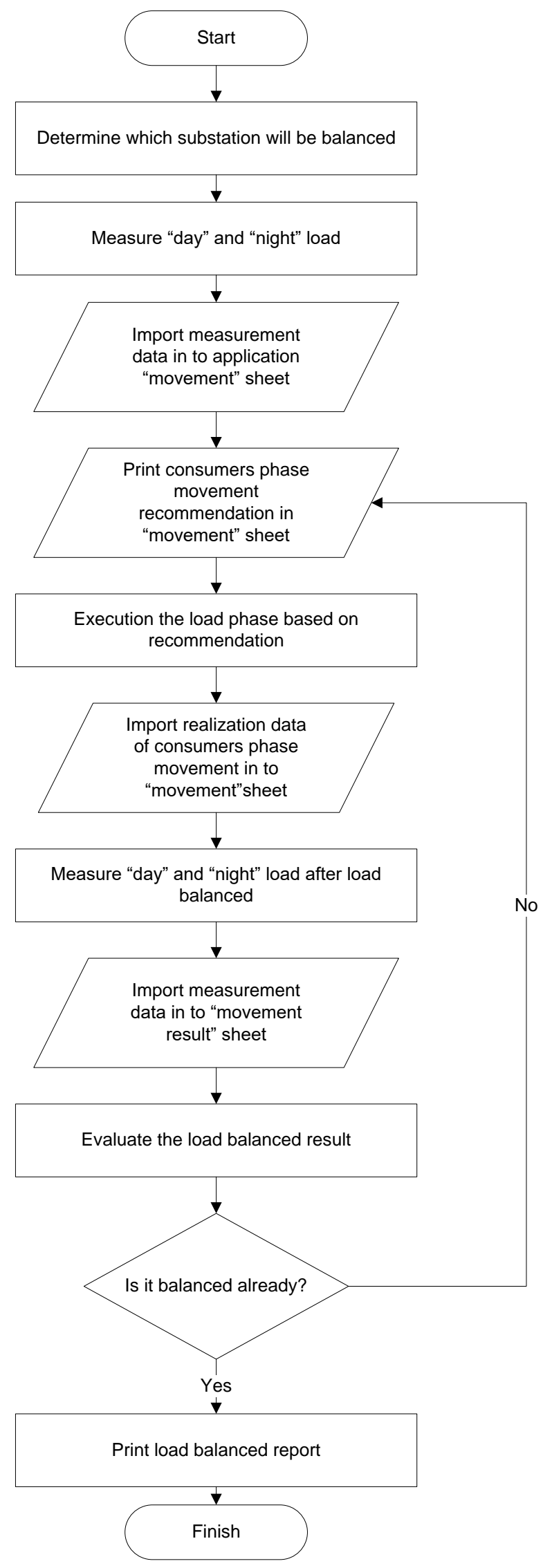

Fig. 1. Flowchart of two-points time method 
Table 1. TJSB Transformer specification

\begin{tabular}{ll}
\hline Brand & $:$ B \& D \\
\hline Power & $:$ 160 kVA \\
\hline Input cables & $:$ A3C $3 \times 150 \mathrm{~mm}^{2}$ \\
\hline Output Cables & $:$ LVTC $3 \times 70+50 \mathrm{~mm}^{2}$ \\
\hline Power factor & $: 0.85$ \\
\hline
\end{tabular}

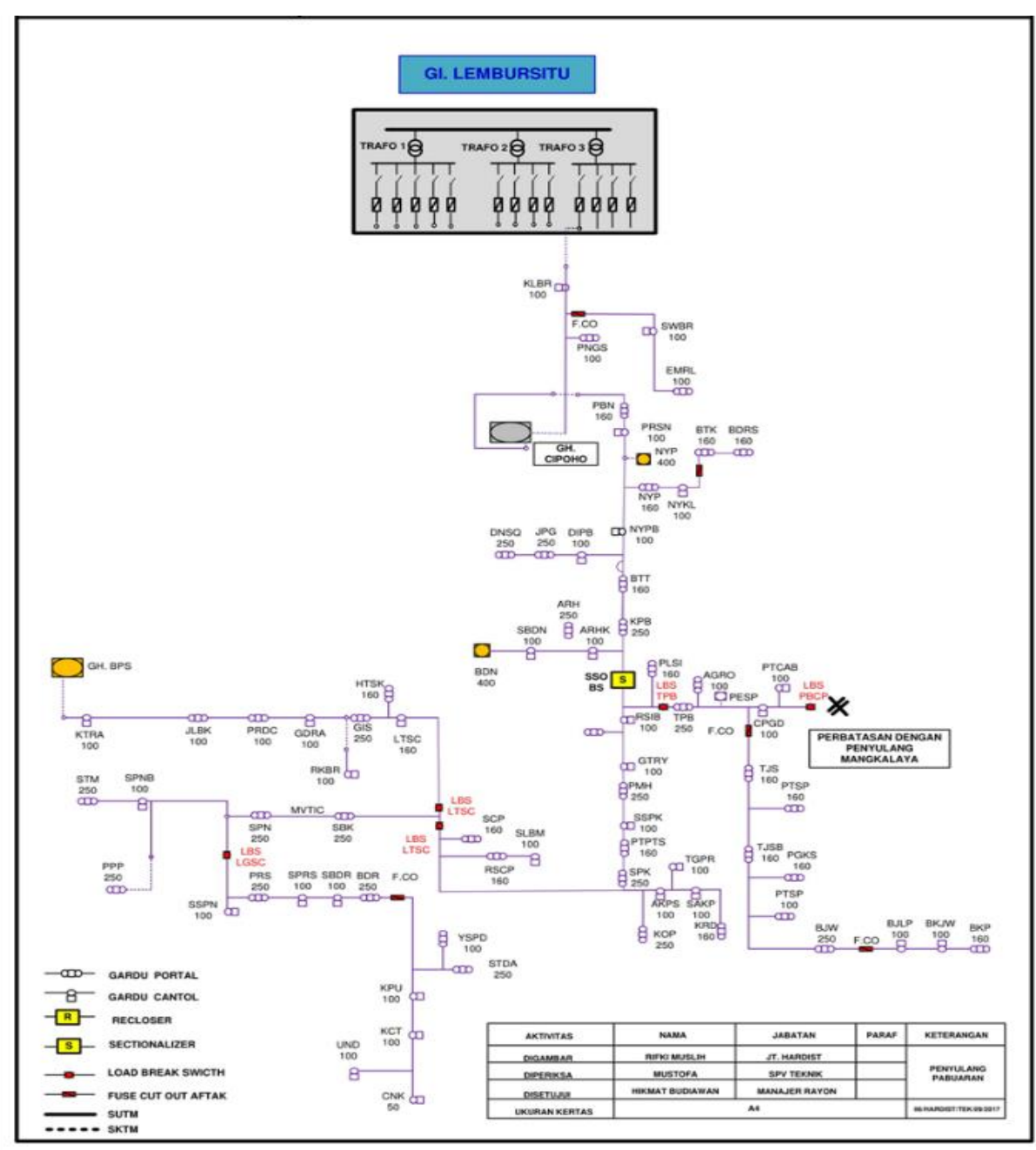

Fig. 2. Pabuaran feeder single line diagram

\subsection{TJSB Transformer Current}

Current measurements are performed on each phase of the TJSB transformer to determine the average of flowing current of phase $R, S$, and T while the number of power losses is determined using neutral current data. The measured current on the TJSB transformer is shown in Table 2.

Table 2. TJSB Transformer current measurement

\begin{tabular}{cc}
\hline $\begin{array}{c}\text { Average Current on Day } \\
(10.00 \mathrm{~s} / \mathrm{d} \text { 15.00) }\end{array}$ & $\begin{array}{c}\text { Average Current on Night } \\
(19.00 \mathrm{~s} / \mathrm{d} 20.30)\end{array}$ \\
\hline Phase current R: 126 A & Phase current R: 208 A \\
\hline Phase current S: 101 A & Phase current S: 147 A \\
\hline Phase current T: 78 A & Phase current T: 113 A \\
\hline Neutral Current: 44 A & Neutral Current: 68 A \\
\hline Ground Current: 24 A & Ground Current: 21 A
\end{tabular}




\subsection{TJSB Transformer Voltage}

Voltage measurements are performed on the distribution transformers on each phase and the phase to neutral voltages can be shown in Table 3.

Table 3. TJSB Transformer voltage measurement

\begin{tabular}{cc}
$\begin{array}{c}\text { Day Average Voltage } \\
(10.00 \mathrm{~s} / \mathrm{d} 15.00)\end{array}$ & $\begin{array}{c}\text { Night Average Voltage } \\
(19.00 \mathrm{~s} / \mathrm{d} 20.30)\end{array}$ \\
\hline Phase Voltage R-S $: 410 \mathrm{~V}$ & Phase Voltage R-S $: 396 \mathrm{~V}$ \\
\hline Phase Voltage R-T $: 406 \mathrm{~V}$ & Phase Voltage R-T $: 400 \mathrm{~V}$ \\
\hline Phase Voltage S-T $: 411 \mathrm{~V}$ & Phase Voltage S-T $: 395 \mathrm{~V}$ \\
\hline Phase Voltage R-N $: 233 \mathrm{~V}$ & Phase Voltage R-N $: 228 \mathrm{~V}$ \\
\hline Phase Voltage S-N $: 234 \mathrm{~V}$ & Phase Voltage S-N $: 228 \mathrm{~V}$ \\
\hline Phase Voltage T-N :236 V & Phase Voltage T-N :229 V \\
\hline
\end{tabular}

\subsection{Resistance Data}

The resistance in phase $\mathrm{N}$ is obtained from the multiplication of $\mathrm{N}$ resistance with the line length, that is $r . L=0.69 \Omega / \mathrm{km} .0 .9916 \mathrm{~km}=0.6842 \Omega$. As shown in Table 4. While the grounding resistance was obtained based on the results of direct measurements in the transformer.

Table 4. Resistance of transformer

\begin{tabular}{cc}
\hline N Phase Resistance $\left(\mathrm{R}_{\mathrm{N}}\right)$ & Grounding Resistance $\left(\mathrm{R}_{\mathrm{G}}\right)$ \\
\hline $0.6842 \Omega$ & $4.3 \Omega$ \\
\hline
\end{tabular}

\section{Result and Discussion}

The measurement data obtained from the measurement result at Sukabumi Kota Region of PT PLN (Persero) can be analyzed to get the percentage of loading, coefficient of unbalance, and power loss as a consideration in determining the load balancing on TJSB transformer.

\subsection{Condition Before Load Balancing}

\subsubsection{Transformer Loading}

Secondary measurement data from TJSB Transformer are illustrated in Fig. 3 and Fig. 4. It was acquired as the result that load in the transformer was unbalanced with a different current in each phase and high value of neutral current.

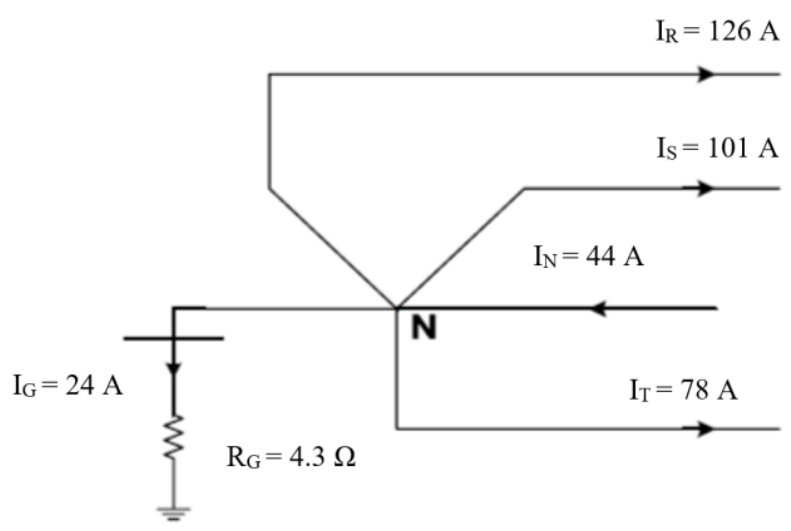

Fig. 3. Transformer secondary current scheme in the day time 


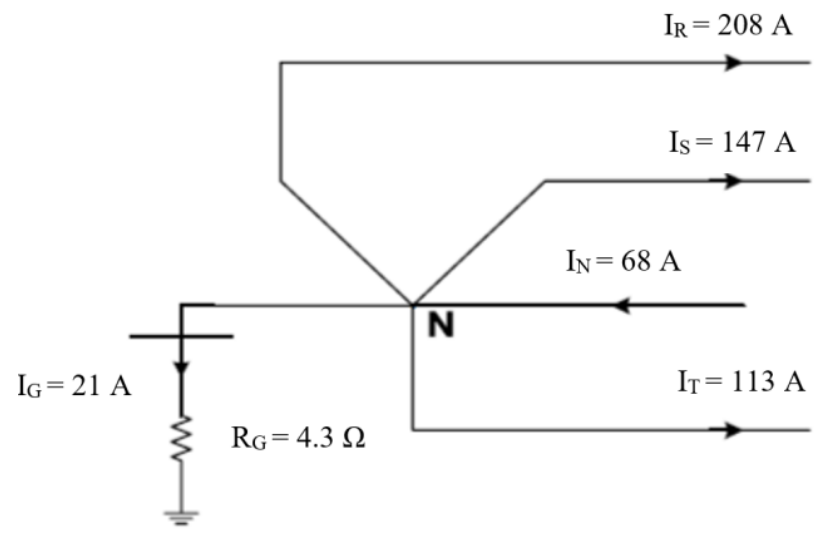

Fig. 4. Transformer secondary current scheme at the night time

The magnitude of the transformer loading percentage is described as follows:

$$
\begin{aligned}
& S=160 \mathrm{kVA}, V_{L L}=390 \mathrm{~V} \\
& I_{F L}=\mathrm{S} /\left(\sqrt{3} \times V_{L L}\right) \\
& I_{F L}=\frac{160,000}{\sqrt{3} \times 390}=\frac{160,000}{692.8}=236.86 \mathrm{~A} \\
& I_{\text {average of day }}=\frac{I_{R}+I_{S}+I_{T}}{3}=\frac{126+101+78}{3}=101.66 \mathrm{~A} \\
& I_{\text {average of night }}=\frac{I_{R}+I_{S}+I_{T}}{3}=\frac{208+147+113}{3}=156 \mathrm{~A}
\end{aligned}
$$

\section{a. Day Loading Percentage}

$$
\frac{I_{\text {average of day }}}{I_{F L}} \times 100 \%=\frac{101.66}{236.86} \times 100 \%=42.9 \%
$$

\section{b. Night Loading Percentage}

$$
\frac{I_{\text {average of night }}}{I_{F L}} \times 100 \%=\frac{156}{236.86} \times 100 \%=65.8 \%
$$

\subsubsection{Transformer Load Unbalance}

The coefficients of each phase and the percentage of transformer TJSB unbalance that occur can be described as follows.

\section{a. Day Load Unbalance Percentage}

Load coefficient in day time can be formulated as:

$$
\begin{aligned}
& a=\frac{I_{R}}{I_{\text {average }}}=\frac{126}{101.66}=1.24 \\
& b=\frac{I_{S}}{I_{\text {average }}}=\frac{101}{101.66}=0.99 \\
& c=\frac{I_{T}}{I_{\text {average }}}=\frac{78}{101.66}=0.77
\end{aligned}
$$

\section{b. Night Load Unbalance Percentage}

Load coefficient at night time can be formulated as:

$$
\begin{aligned}
& a=\frac{I_{R}}{I_{\text {average }}}=\frac{208}{156}=1.33 \\
& b=\frac{I_{S}}{I_{\text {average }}}=\frac{147}{156}=0.94 \\
& c=\frac{I_{\boldsymbol{T}}}{I_{\text {average }}}=\frac{\mathbf{1 1 3}}{\mathbf{1 5 6}}=0.72
\end{aligned}
$$


Load unbalance percentage in night time:

$$
\begin{aligned}
& =\frac{\{|a-1|+|b-1|+|c-1|\}}{3} \times 100 \% \\
& =\frac{\{|\mathbf{1}, \mathbf{3 3}-\mathbf{1}|+|\mathbf{0}, \mathbf{9 4}-\mathbf{1}|+|\mathbf{0}, \mathbf{7 2 - 1}|\}}{\mathbf{3}} \boldsymbol{x} \mathbf{1 0 0} \%=25.6 \%
\end{aligned}
$$

\subsubsection{Power Losses}

The number of power losses occurring in the transformer can be calculated using equations (1) and (2), so the results can be seen in Table 5. It can be concluded from the table that the amount of load unbalance and neutral currents are directly proportional to the amount of loss of power at the transformer.

Table 5. Power losses

\begin{tabular}{ccc}
\hline Time & $\mathrm{P}_{N}(\mathrm{~kW})$ & $\mathrm{P}_{\mathrm{G}}(\mathrm{kW})$ \\
\hline Day & 1.32 & 2.47 \\
\hline Night & 3.16 & 1.89 \\
\hline
\end{tabular}

\subsection{Balancing Recommendation using Two-Points Time Method}

The input of the two-point time method is a direct measurement of the current, voltage and resistance of the TJSB transformer per-phase. Using the two-point time (day and night) method on the application sheet, a consumer's phase transfer recommendation was obtained as shown in Table 6

Phase transfer recommendation to consumers is by looking from line 1 and line 2 while the source is the total sum of all line. It can be seen that phase $R$ has a value of -19.6442 , means that line must be moved in phase $\mathrm{S}$ as much as $2.5 \mathrm{~A}$ and phase $\mathrm{T}$ as much as $17.1 \mathrm{~A}$.

Table 6. Balancing recommendation using two-points time method

\begin{tabular}{cccccc}
\hline \multicolumn{7}{c}{ Consumers Phase Movement Recommendation } \\
\hline Phase & Line 1 & Line 2 & Line 3 & Line 4 & Source \\
\hline R & -19.6442 & -14.2801 & 0 & 0 & -33.9243 \\
\hline S & 2.53707 & 3.33444 & 0 & 0 & 5.87152 \\
\hline$T$ & 17.1071 & 10.9456 & 0 & 0 & 28.05282 \\
\hline
\end{tabular}

Based on the recommendation from Table VI then that is obtained a different percentage of the load to unbalance between before and after a recommendation of load movement. The comparison is illustrated in Fig. 5 and Fig. 6.

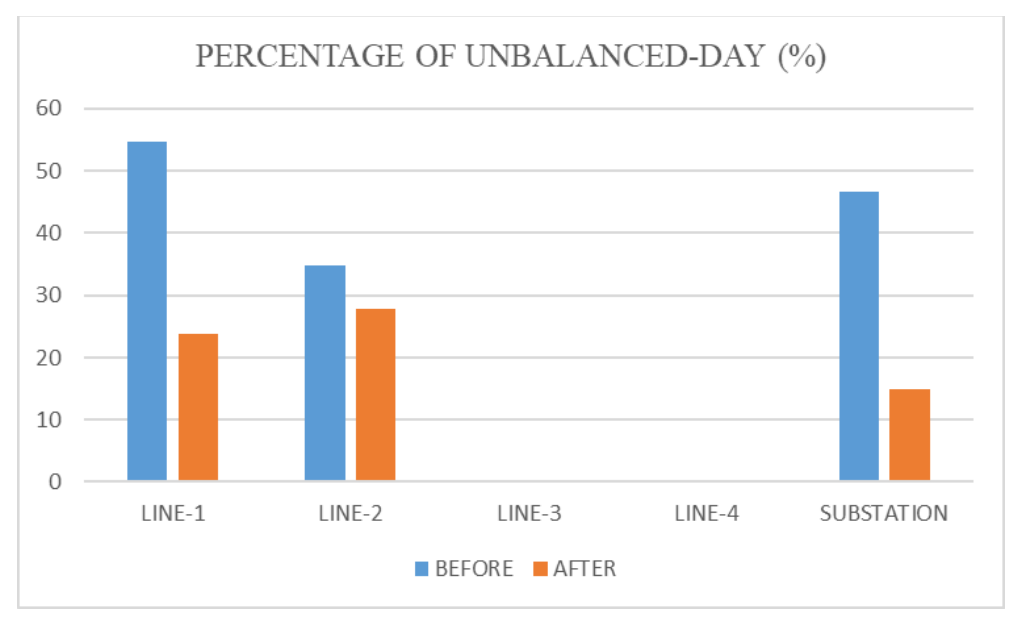

Fig. 5. Load unbalance percentage in the day time 


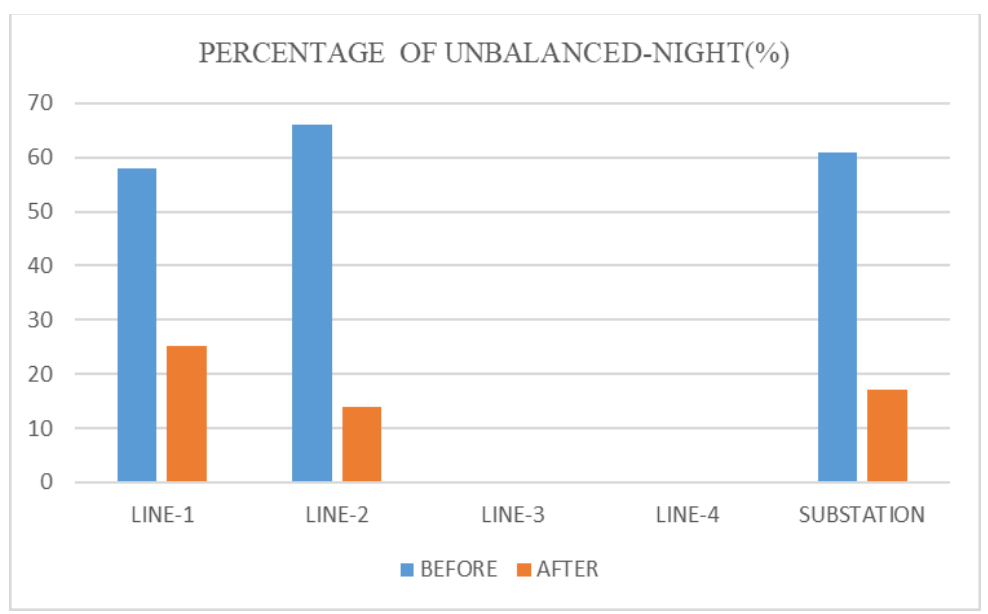

Fig. 6. Load unbalance percentage in the night time

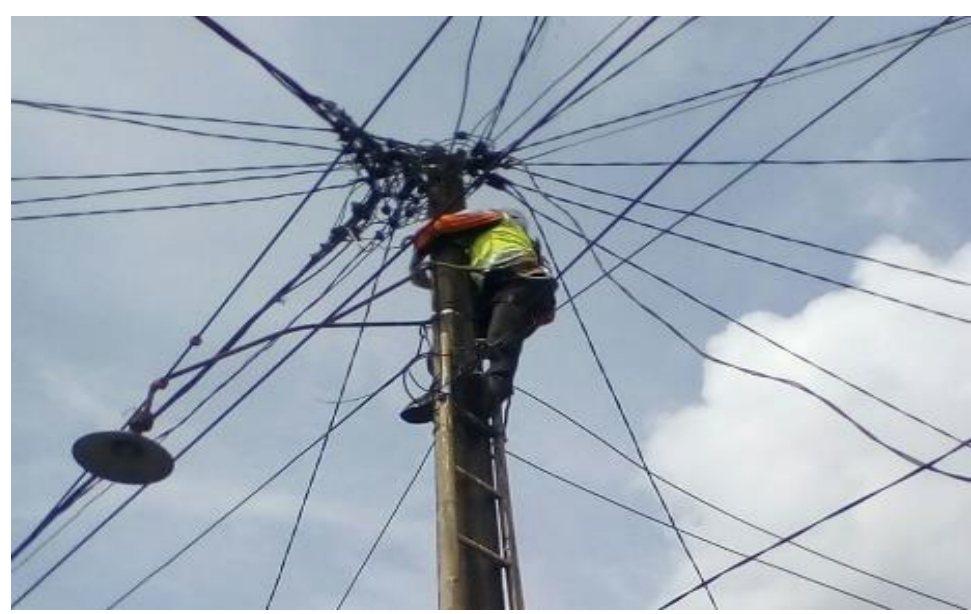

Fig. 7. Realization of consumers phase load movement

Consumers phase load movement was done by moving some home load from one phase to another phase. The realization of consumer phase load movement work can be seen in Fig. 7 . The load movement was done by 3 people from the engineering maintenance team, with the description of each job were:

a. Checking power by referring to the number in Miniature Circuit Breaker (MCB) which was close from low voltage network pole.

b. Determining load using ampere pliers in connection panel for those in the substation.

c. Moving phase by moving the house line in low voltage network pole.

After the transfer and load balancing were done then the value of current, voltage and phase resistance per line were recorded, thus it could be evaluated on the work that has been done.

\subsection{Condition after Load Balancing}

Secondary current measurement data of TJSB Transformer after load balancing realization is shown in Fig. 8. And Fig. 9. 


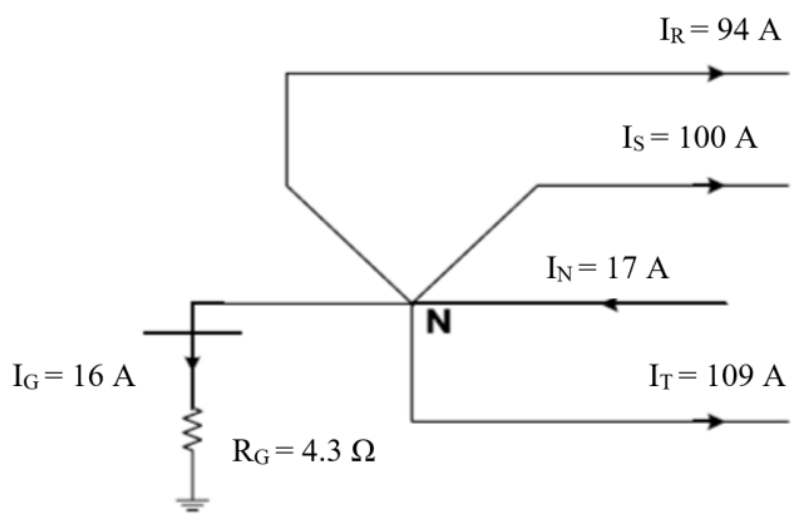

Fig. 8. Day time transformer current after load balancing

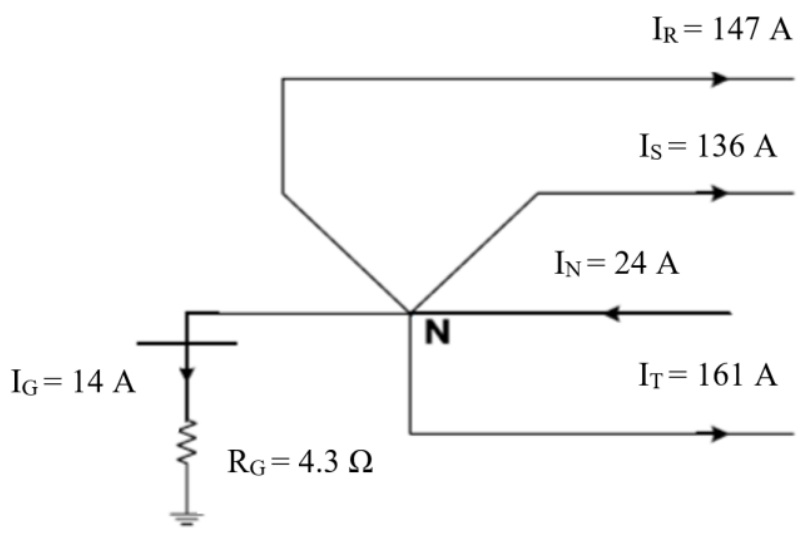

Fig. 9. Night Time transformer current after load balancing

Re-calculation was done to obtain the percentage of transformer loading after load balancing. Comparison of current and percentage of transformer loading before and after load balancing can be seen in Table 7 .

Table 7. Comparison of transformer loading percentage

\begin{tabular}{lcccc}
\hline \multirow{2}{*}{ Time } & \multicolumn{2}{c}{ Laverage $(\mathrm{A})$} & \multicolumn{2}{c}{ Percentage $(\%)$} \\
\cline { 2 - 5 } & Before & After & Before & After \\
\hline Day & 101.66 & 101 & 42.9 & 42.6 \\
\hline Night & 156.00 & 148 & 65.8 & 62.4 \\
\hline
\end{tabular}

Furthermore, load unbalances determination after the movement was done shown in Table 8.

Table 8. Comparison of load unbalance percentage

\begin{tabular}{ccc}
\hline Time & \multicolumn{2}{c}{ Percentage $(\%)$} \\
\hline & Before & After \\
\hline Day & 16.0 & 5.0 \\
\hline Night & 25.6 & 5.6 \\
\hline
\end{tabular}

Table 9. Comparison of load losses caused by neutral current

\begin{tabular}{ccccc}
\hline \multirow{2}{*}{ Time } & \multicolumn{2}{c}{$\mathrm{PN}_{\mathrm{N}}(\mathrm{kW})$} & \multicolumn{2}{c}{ Percentage $(\%)$} \\
\cline { 2 - 5 } & Before & After & Before & After \\
\hline Day & 1.32 & 0.19 & 1.0 & 0.13 \\
\hline Night & 3.16 & 0.39 & 2.3 & 0.28 \\
\hline
\end{tabular}


Table 10. Comparison of power losses caused by ground current

\begin{tabular}{ccccc}
\hline Time & \multicolumn{2}{c}{$\mathrm{PG}_{\mathrm{G}}(\mathrm{kW})$} & \multicolumn{2}{c}{ Percentage (\%) } \\
\cline { 2 - 5 } & Before & After & Before & After \\
\hline Day & 2.47 & 1.10 & 1.8 & 0.80 \\
\hline Night & 1.89 & 0.84 & 1.4 & 0.61 \\
\hline
\end{tabular}

Table 8. explains that load unbalances percentage before and after load balancing using two-point times are significant. After load balancing, the percentage of load unbalance is below the standard limit of PLN Surat Edaran Direksi No.040.E/152/DIR/1999 about "Guidance of distribution system management" which is $25 \%$. Table 9. and Table 10. explained power losses are caused the neutral current in the transformer mostly appear at night meanwhile power losses are caused neutral current to ground is mostly generated in peak load. The effect of neutral current can produce an excess hit in transformer and decreases in power quality.

\section{Conclusion}

Two-points time methods propose load balancing by addition of load in R-phase as much 19.644 in line 1 and 14.280 in line 2. The deficit can be supply from the accumulation of S-phase as much 2.537 in line 1 and 3.334 in line 2 and T-phase as much 17.107 in line 1 and 10.945 in line 2. This recommendation can be the solution in load unbalance, neutral current as well as power losses problems. Day load unbalances percentage decreased from $16 \%$ to be $5 \%$, while night load from $25.6 \%$ to be $6 \%$. Neutral current formerly occurred as $44 \mathrm{~A}$, decreased to be $16 \mathrm{~A}$ in the day time and from $68 \mathrm{~A}$ to be $24 \mathrm{~A}$ in the night time. Besides that, power losses were also able to be reduced until $1.1 \mathrm{~kW}$ in the day and $0.84 \mathrm{~kW}$ in the night time.

\section{Reference}

[1] Abdelhay A. S. and O. P. Malik, "Electric Distribution Systems", 2011, published by John Wiley \& Sons.

[2] Gonen, T. "Electric Power Distribution System Engineering", 2008. New York: CRC Press Taylor and Francis.

[3] Chen J, Y. Y. Yajuan, S. Jian, and L. Bin. "Research and Application of Load Balance Approach for Distribution Based on Big Data". International Conference on Electricity Distribution. Xi'an. 2016: 1-6.

[4] Atabak N., I. Iskender, N. Gene. "Evaluating and De-rating of three-phase distribution transformer under unbalanced voltage and unbalance load using finite method". IEEE 8th International Power Engineering and Optimization Conference. Langkawi. 2014: 160-165.

[5] Basit A., I Siddique. "Distribution System Loss Reduction by Automatic Transformer Load Balancing". 20th International Multi-topic Conference. 2017: 1-5.

[6] Kartik P. B. and M. George. "Maintaining balanced three-phase load voltage during singlephase auto-reclosing in medium voltage distribution lines". IET Generation, Transmission \& Distribution. 2013. Vol. 8, ISS. 5, pp. 798-802.

[7] Chun, L.S., Yu-Chi P., Hai-Ming C., Chao-Lin K., "Design of transformer load monitoring systems by utilizing smart meter data". IEEE Conference. 2017: 88-92.

[8] P. Houman, W. J. Peter. "Impact of High Penetration on Distribution Transformer Insulation Life". IEEE Transaction on Power Delivery. 2014. Vol. 29, No.3. pp. 1212-1220.

[9] Tzu Hung, Chang, T.E., Lee,C., and H. Lin. "Distribution network reconfiguration for load balancing with a colored petri net algorithm. IEEE International Conference on Applied System Innovation. Me-en. 2017: 1040-1043.

[10] H, Tianqi, F. Leon. "Controlling non-synchronous micro-grids for load balancing of radial distribution systems". IEEE Transaction on Smart Grid. 2017. Vol. 8., No.6, pp: 2608-2616.

[11] Z, Jianqiao, W. Jiacheng. "Multi-bus flexible interconnection scheme for balancing power transformers in low voltage distribution systems". IEEE Conference. 2017: 6401-6406. 